\title{
Are points like money? An empirical investigation \\ of reward promotion effectiveness for multi-category retailers
}

\begin{abstract}
Point-based frequency reward programs are widely used by retailers as a sales promotion strategy. To promote a specific product category, retailers offer more favorable reward ratios so that members can earn extra points. This paper examines the impact of reward ratio variations on sales in a multicategory setting, and compares the effectiveness of the reward and price promotion strategies. We estimate a multivariate probit model using scanner data of member purchases in four categories, grouped into two category pairs. We found that increasing the reward ratio in a category positively affected its choice probability and that the presence of rewards promotions also had positive impact on the choice probability of nonpromoted but closely related category within the same category pair. As forms of sales promotion, price discounts and reward promotions were shown to substitute for each other. We constructed and computed a measure, the rate of substitution, to quantify the effects of substitution. The financial implications of holding reward promotions are computed and discussed.
\end{abstract}

Keywords: Sales promotion, cross-category purchases, frequency reward programs, shopping behavior, elasticity, rate of substitution. 


\section{Introduction}

"But what is a mile worth? Airlines sell them to credit-card firms at an average of just under 2 cents a mile; their value when used to buy a ticket or to upgrade to business class can be anywhere between 1 cent and over 10 cents per mile."

"Yet the dollar ... has been superseded not by the euro, nor by the yen or yuan, but by another increasingly popular global currency: frequent-flyer miles.”

-- The Economist, 2005

Frequency reward programs have become commonplace in the retail industry, leading to a proliferation of reward points. Retailer rewards have become far more sophisticated than the traditional offer of "buy one get one free.” Indeed they are very similar to those offered by airlines and credit card companies in that the members receive and accumulate points based on their purchases and may exchange them at any time for rewards largely proportional to the number of points redeemed (Berman 2006). Together they sometimes are referred to as “reward currencies” (Postrel \& Hlavinka 2012). But what are the points worth?

There are several perspectives on evaluating reward points. First, retailers usually impose rules on the “exchange rate” between monetary payments and reward points in both earning and redemption. As with airline miles, retailer reward points can be treated as an alternative currency—at least within the retailer's location. Such “reward ratio,” or the points-per-dollar rate, is an objective measure of the points' worth. Second, the consumers' subjective perceptions of reward points may not be consistent with their actual monetary value (Drèze and Nunes 2004). We propose a third approach to understanding the worth of reward points to consumers by examining the relationship between retail promotions using price reductions and offering more reward points. We construct and compute a novel measure, the rate of substitution, to quantify the effects of substitution.

The acts of awarding and redeeming points represent opportunities for retailers to implement promotions. For instance, retailers may allow members to earn more reward points at higher points-tospending ratios over a limited period of time and/or for some limited categories. Such reward promotions are similar to price reductions in that they stimulate sales during specified promotional periods due to the points pressure effect where “customers increase their purchase rate in an effort to earn a reward” (Taylor 
and Neslin 2005). But promotions with prices and reward points are also quite different in many important ways: price promotions may be more effective because the benefits for consumers are immediate and liquid, whereas reward promotions can provide consumers with psychological benefits (Henderson et al. 2011). This research aims to answer the following question: As a sales promotion strategy, how effective are reward promotions compared to price discounts?

To quantify the relationship between the strategies, we have constructed the rate of substitution between price and reward promotions. It is defined as the ratio between a $1 \%$ change in prices and a percentage change in reward ratios that, when applied together, cause no change in the consumers' utility of a particular category. Our empirical results show that reward promotions effectively increase sales of the promoted category, and also have a positive effect on sales in other categories. We consider four categories grouped into two pairs: facial care and personal hygiene. The results indicate that reward promotions can serve as a substitute for price discounts to stimulate sales. Moreover, an analysis of the profit implications shows that the return on the investment in reward promotions can be high enough to be profitable for the retailer.

This research is related to and contributes to three streams of literature. First, it provides a new perspective to understand the implications of reward program for consumers and the firms operating it. Most existing research on reward programs focuses on behavioral questions, in particular whether and how they affect customer loyalty and retention (Bolton, Kannan, and Bramlett 2000; Keh and Lee 2006; Kivetz, Urminsky, and Zheng 2006; Lewis 2004; Liu 2007; Melnyk and van Osselaer 2012; Yi and Jeon 2003). The literature on marketing and customer relationship management (CRM) has dealt extensively with the use of reward programs in purchase tracking (Mauri 2003) and their role in price discrimination (Hartmann and Viard 2008). Researchers have also noticed an intriguing lack of empirical studies concerning the immediate effect of reward promotions on short-term sales (Bolton et al. 2000; Drèze and Hoch 1998; Lal and Bell 2003; Lewis 2004). We examine the use of points-based program as a strategy of sales promotion. It is worth emphasizing that the focus of this study is not reward programs per se, but 
the sales impact of reward promotions ${ }^{1}$. Though repeat patronage and shopper information collection are clearly desirable benefits, it is equally important for academics and marketers to understand and explore other creative uses of reward programs.

A small and growing literature has studied the use of reward programs as sales promotion. Zhang and Breugelmans (2012) investigate the impact of an item-based loyalty program where under which price discounts are replaced by the opportunity to earn extra reward points as a form of retail sales promotion. Dorotic et al. (2011) focus on the own- and cross-vendor effects on each participating vendor's sales. Our research departs from their study by investigating how the reward promotion in one category affects other categories at a retailer.

Second, as this research studies the effectiveness of reward promotions in the context of multicategory retailing, it also builds on the empirical research on market basket analysis in particular the cross effects of price promotions (Duvvuri, Ansari, and Gupta 2007; Leeflang and Parreño-Selva 2012; Manchanda, Ansari, and Gupta 1999; Russell et al. 1999; Seetharaman et al. 2005). A typical retailer carries hundreds of categories at a single location, and the consumers' response to price changes and promotional activities varies significantly from category to category (Narasimhan, Neslin, and Sen 1996). Moreover, a promotion can affect sales in nonpromoted categories. In order to design optimal pricing and promotion strategies, retailers must understand these effects and coordinate their marketing activities across multiple product categories. As such, the primary purpose of this study is to analyze the effects of price reductions and increased reward ratios both within and across categories. Such cross-category effect would be of interest to retailers as they usually carry thousands of categories. Moreover, this present study attempts to understand the relationship between alternative promotion strategies, in particular, those using reward point increases and those using price reductions. As such, our study contributes to the research on sales promotions by providing further insights into the use of reward programs.

The rest of the paper is organized as follows. We begin with a description of the data and the

\footnotetext{
${ }^{1}$ In the following discussion, we use the term "reward ratio" to refer to the number of reward points a consumer earns for every unit of money spent on particular purchase. Therefore, reward promotions correspond to events in which reward ratios are above the regular level.
} 
retailer's reward scheme. Section 3 explains the empirical model, followed by the discussion of the empirical findings. In the final section, we draw conclusions and offer some thoughts on directions for future research.

\section{Data description}

The data in this study were collected at a retailer in a large port city in northeastern China. It comprises the transaction records of all members of the reward program, including the number of reward points awarded. The reward program has a simple, point-based design. Shoppers who spend more than $300 \mathrm{yuan}^{2}$ at the retailer are eligible to become members. Membership is terminated if no purchase is made for over a year. Reward points are accumulated by using the membership card at the checkout; one point is awarded for every 10 yuan spent on low-value, frequently purchased categories such as skincare, apparel, and footwear. (That is, the base reward ratio is 0.1). The points accumulated can later be redeemed at a ratio of 10 points for 1 yuan. This suggests that each reward point costs the retailer 0.01 yuan if redeemed. The retailer often raises the reward ratio as a sales promotion tool. For example, in our dataset the reward ratio sometimes goes as high as 2 points per yuan, twenty times the regular rate. Such promotions accelerate point accumulation and are likely to stimulate sales in other categories carried by the retailer.

The transaction dataset contains 69,379 weekly observations for 17,171 loyalty program members between January 2005 and May 2006. Table 1 presents an overview of the member purchasing histories. About 22\% of members purchased from the retailer on more than six occasions during the study period. Nearly 30\% of members purchased only once. Among the many available product categories, we focus on a subset of four: two facial care products (facial lotion and facial mask) and two personal hygiene products (shampoo and body wash). Facial care and personal hygiene products are located in different floors with separate checkout counters at this retailer, but the reward points are recorded to the same membership account.

2 Yuan is the unit of the Chinese currency and was approximately worth 1/7 U.S. dollar for the data period. 
(Insert Table 1 around here.)

The variables in the dataset include a member ID, demographic information of the members such as age and gender, the categories and brands in each basket, the purchased quantities, the prices paid, ${ }^{3}$ the number of reward points earned for each transaction, the dates of purchase, and cumulative point totals. Table 2 shows the summary statistics of the prices and reward ratios. It is apparent that the two facial care categories are quite distinct from the two personal hygiene categories in terms of both prices and reward ratios. For example, facial lotions have by far the largest price dispersion, and the most expensive lotion costs hundreds of times more than the cheapest one. We constructed an indicator variable for reward promotion. As the regular reward ratio is 0.1 , when a category is offering a reward promotion, its reward ratio will be higher than the regular level of $0.1($ RPromo $=1)$. Thus, the third panel in Table 2 shows that facial lotion and mask are much more frequently promoted with higher reward ratios across all the observations (39\% and 82\% respectively) than shampoo and body wash (7\% and 10\% respectively). The bottom panel of Table 2 presents summary statistics on the member-specific information, including age, gender and cumulative points at the time of each purchase. Among the reward program members in this dataset, $86 \%$ are female and on average 36.4 years old (with the youngest at 16 and the oldest at 79 ).

(Insert Table 2 about here.)

In the data, at least one category was purchased on 30,431 occasions and no purchase was made on the remaining 38,948 occasions (43.9\%). The number of pairwise incidence across all four categories is presented in Table 3. Among two-category baskets, the categories most frequently purchased together are facial lotion and facial mask (738), followed by shampoo and body wash (670), both are within the category pair. The joint purchases across the two pairs are rare. Thus, we consider the four categories as two separate pairs: the facial care pair includes the lotion and the facial mask, whereas the personal hygiene pair contains shampoo and body wash. As the small number of joint purchases across pairs make

3 The prices are standardized as items within the same category may be sold in packages of different sizes, or be measured in a variety of units (milliliters or grams in the case of facial lotions, number of pieces in the case of facial masks, bottles of different sizes for shampoos), hence impossible to compare prices directly. The details of price standardization are available from the authors upon request. 
identification of the cross-pair effect unreasonable, we investigate the cross effects within each pair only.

(Insert Table 3 about here.)

\section{Model and identification}

In this section we first describe a generic random utility model for multicategory basket purchases and then apply it to the retail dataset. The model is adapted from Manchanda, Ansari and Gupta (1999) which have also investigated the effects of prices and promotions on consumer multicategory purchase incidences. Our model is based on the notion of latent utility; specifically, a typical consumer $k(k=1$, $2, \ldots, K)$ will make a purchase in a category $i$ only if the utility from purchasing the category is positive. Hence, we have the following link between observed category choice variable and latent utilities,

$$
C_{k i t}= \begin{cases}1, & \text { if } U_{k i t}>0 \\ 0, & \text { if } U_{k i t} \leq 0\end{cases}
$$

Consumer $k$ purchases a basket $B_{k t}$ comprising $n$ product categories from the retailer at time $t$. Thus $B_{k t}$ is an $n$-dimensional vector of binary variables $C_{k i t}$, which denotes the consumer decision whether to make a purchase in category $i$; that is, $B_{k t}=\left(C_{k 1 t}, C_{k 2 t}, \ldots, C_{k n t}\right)$. These category purchase incidence variables take on the value 1 if category $i$ is purchased and 0 otherwise.

We assume that consumer $k$ 's indirect utility for purchasing category $i$ at time $t$ is given by:

$$
\begin{aligned}
U_{k i t}= & \beta_{i 0}+\left(\beta_{k i p}+\beta_{i s} \text { PPromo }_{k i t}\right) \text { Price }_{k i t}+\beta_{k i r} \text { RRatio }_{k i t} \\
& +\sum_{j \neq i} \beta_{i p}^{j} \text { Price }_{k j t}+\sum_{j \neq i} \beta_{i r}^{i} \text { PPromo }_{k j t}+\varepsilon_{k i t}, \quad \text { for } i=1,2, \ldots, n
\end{aligned}
$$

where Price $_{\text {kit }}$ is the standardized price of category $i$ at time $t$, RRatio $_{k i t}$ is the reward ratio of category $i$ at time $t$, and $R P r o m o_{k j t}$ is a binary variable indicating whether there is a reward promotion in category $i$ at

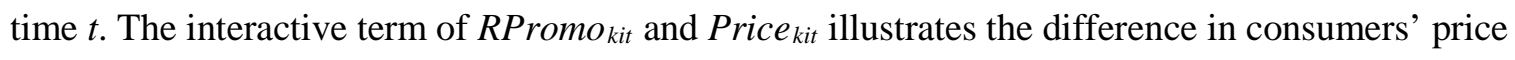
sensitivity during reward promotions as compared to the no-promotion periods. These variables are all individual-specific.

The observable part of the latent utility of each category has two components: the own effects and the cross effects. The own effects come from the self-category price and reward, $\left(\beta_{k i p}+\beta_{i s} R\right.$ Promo $\left._{k i t}\right)$ Price $_{k i t}$ 
$+\beta_{k i r} R R a t i o_{k i t}$, while the cross effects come from the cross-category marketing mix, $\sum_{j \neq i} \beta_{i p}^{j} P_{r i c e} e_{k j t}+\sum_{j \neq i}$

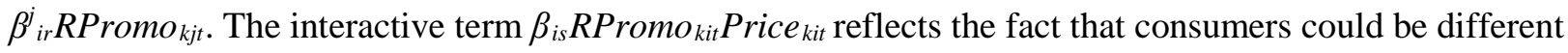
in price sensitivity during periods of reward promotion, and its coefficient measures the changes in consumers' price sensitivity during the reward promotion.

The coefficients for self-category price and reward ratio are heterogeneous across individuals, depending on the individual-specific characteristics. To this end, we assume $\beta_{k i p}=D_{k} \lambda_{i p}$ and $\beta_{k i r}=D_{k} \mu_{i r}$ for price and reward ratio coefficients, respectively. Here $D_{k}$ is a vector of individual-specific characteristics for member $k$ and consists of sex (1 if female), age, and cumulative reward points of the consumer. The parameters $\lambda_{i p}$ and $\mu_{i r}$ are vectors of coefficients for price and reward ratios, respectively. The cross-effects parameters are homogeneous across consumers.

The unobservable utility terms $\varepsilon_{k i t}$ are assumed to be independent across consumers and time periods, but the idiosyncratic unobservable utilities are correlated across categories for each individual, so we assume $\varepsilon_{k i t} \sim \operatorname{MVN}(0, \Sigma)$, where $\Sigma$ is covariance matrix of $\varepsilon_{k i t}$. As we assume that the variances of the random terms are identical across categories and standardized to one, the diagonal elements of the covariance matrix are unity. The off-diagonal terms, $\rho_{i j}$, are the correlation between categories $i$ and $j$ that drive joint purchases.

Our assumption on the error terms results in a multivariate probit model, allowing for simultaneous purchases of multiple categories. The probability of observing a shopping basket incidence, conditional on the model parameters and covariance matrix, is given by

$$
\operatorname{Pr}\left(B_{k t}=b_{k t} \mid \beta, \Sigma\right)=\int_{\mathrm{A}} f\left(\varepsilon_{k t}\right) d \varepsilon_{k t}
$$

where $\varepsilon_{k t}$ is a vector of random terms for all categories $i$ for consumer $k$ at time $t$, and $f\left(\varepsilon_{k t}\right)$ is the joint density function of $\varepsilon_{k t}$. The integration interval $\mathrm{A}$ is determined by the purchase incidence of each category: for those categories with $C_{k i t}=1$, the interval is $(0, \infty)$; for those with $C_{k i t}=0$, this interval is $(-\infty, 0]$. The likelihood across all consumers is

$$
L=\prod_{k=1}^{K} \operatorname{Pr}\left(B_{k t}=b_{k t} \mid \beta, \Sigma\right) .
$$


Maximum likelihood estimation (MLE) is used to estimate the utility function parameters $\beta$ and the covariance matrix $\Sigma$.

To explicitly measure the effectiveness of reward point promotions vis-à-vis price promotions, we construct two measurements, rate of substitution and return on investment.

Rate of substitution $\left(R S_{k i t}\right)$ is defined as changes in the reward ratio that are necessary to offset the disutility resulted from 1\% price increase while keeping the utility unchanged in category $i$ for consumer $k$, or formally $R S_{k i t}=\mathrm{d} R$ Ratio $_{k i t} /\left(\mathrm{d}\right.$ Price $_{k i t} /$ Price $\left._{k i t}\right)$. From the utility function, we have the following condition $\mathrm{d} U_{k i t}=\frac{\partial U_{k i t}}{\partial \text { Price }_{k i t}} d$ Price $_{k i t}+\frac{\partial U_{k i t}}{\partial r_{k i t}} d R$ Ratio kit $=0 .{ }^{4}$ Thus, we have

$$
R S_{k i t}=-\frac{\beta_{k i p}}{\beta_{k i r}}
$$

Eq. (5) implies that the rate of substitution is essentially the ratio of the price coefficient and the reward ratio coefficient in the consumer utility function. It measures the incremental points necessary to offset the disutility of $1 \%$ price increase. A higher $R S_{\text {kit }}$ suggests that, for consumer $k$ in category $i$, the impact of a $1 \%$ price change on utility, as compared to that of a reward ratio change, is greater. During a reward promotion when the reward ratio is higher than 0.1 , the reward promotion will be more costly than $1 \%$ price discount. ${ }^{5}$ In categories with higher $R S_{k i t}$, the retailer has to offer more rewards whose cost is already more than $1 \%$ price discount. We calculate the average $R S_{i}$ across all consumers in each category $i$ and report them in the next section.

Return on investment $(R O I)$ of reward promotions is defined as the incremental profit contribution generated from each yuan invested in reward promotions. ${ }^{6}$ Formally, the ROI of consumer $k$ from the retailer investment in the extra reward points during promotions in category $i$ is

$$
R O I_{k i}(\gamma)=\frac{\sum_{j} \Delta_{i} \operatorname{Pr}\left(C_{k j}=1\right) \times \text { Price }_{k j} \times \gamma}{\sum_{j} \Delta_{i}\left[\operatorname{Pr}\left(\mathrm{C}_{k j}=1\right) \times \text { Price }_{k j} \times \text { RRatio }_{k j}\right] \times 0.1}
$$

where $\gamma$ is the profit-to-revenue ratio. In Eq. (6), $\Delta_{i} \operatorname{Pr}\left(C_{k j}=1\right)$ is the change of purchase incidence in

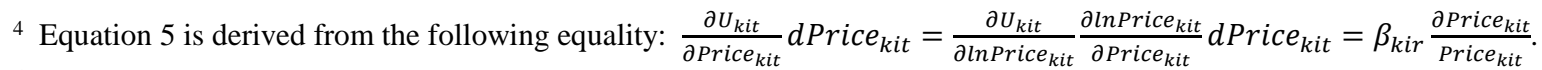

5 Since the regular reward ratio at the retailer is 0.1 reward point for each yuan spent, and one reward point can be redeemed for 0.1 yuan, assuming all reward points are redeemed eventually, the effective costs for the retailer is equivalent to $1 \%$ price cut.

${ }^{6}$ We are indebted to an anonymous reviewer for suggesting this analysis.
} 
category $j$ due to the reward ratio changes in category $i$. The numerator represents the total profits due to the reward ratio change in category $i$, summed across all categories $j$., which stems from the changes of purchase incidence due to the reward ratio changes. Similarly, $\Delta_{i}\left[\operatorname{Pr}\left(C_{k j}=1\right) \times\right.$ Price $_{k j} \times$ RRatio $\left._{k j}\right]$ is the change in total number of reward points due to reward ratio changes in category $i$. Given that each reward point is worth 0.1 yuan when redeemed, the denominator represents the total cost of the reward points, assuming consumer $k$ redeems all points eventually.

\section{Empirical findings}

As the observed joint purchases of commodities across pairs are relatively rare, we assume that the correlation of the unobservable utilities, $\rho$, to be zero for any cross-pair categories. This assumption allows us to estimate the parameters jointly by applying multivariate probit model to two pairs with constraints on $\rho$. Table 4 shows the observed and predicted purchase incidences from our empirical model using the estimation sample. The predicted numbers are highly consistent with the observed cases and the hit rates are $99.52 \%$ and $99.64 \%$ for the two category pairs respectively, indicating good model fit and high predictive ability.

(Insert Table 4 here.)

\subsection{Effects of marketing variables and consumer-specific characteristics}

Own effects. We report the estimates in Table 5. The estimated choice model suggests that, as expected, own prices have a negative and statistically significant impact on choice share in all four categories $\left(\operatorname{lnPrice}_{i}\right)$. Own effects of reward ratios are positive and statistically significant for all categories $\left(\right.$ RRatio $\left._{i}\right)$.

\section{(Insert Table 5 here.)}

The coefficients of the interactive term, PPromo_Price $_{i}=$ RPromo $_{i} \times \ln$ Price $_{i}$, are found to be negative and significant in all four categories, suggesting that when category $i$ is having a sales promotion by offering higher reward ratios, shoppers are more price-sensitive. This suggests that a price reduction can be more effective in increasing purchases in that category. 
The demographic characteristics showed different influence on purchase incidence across the two category pairs. In the pair of facial skincare products, the gender of the loyalty card holder does not have a significant effect on purchase incidence but age does: consumers’ price sensitivity increases in age. These results seems to be consistent with anecdotal evidence that young consumers value their appearance more than their older counterparts do and consider the use of facial skincare essential for their personal life and career. In contrast, for the pair of personal hygiene categories female members are found to be significantly more price-sensitive. This could be explained by that the personal hygiene products are perceived more as necessities than the other pair. The coefficient for the interactive term of own reward ratio and cumulative reward points are negative and significant in the two personal hygiene products. This finding implies that reward program members who have accumulated many points are less responsive to the reward ratios in that category.

Cross-effects. We are also interested in the within-pair, cross-category effect of price and reward point promotions. The cross-category price effects between the two facial skincare products are positive, suggesting a substitute relationship between facial lotion and mask, whereas shampoo and body wash are typical complements judging from the negative cross-category price coefficients (Duvvuri et al. 2007). The high average prices of facial lotion and masks imply that each of them alone can impose a large burden on the shoppers' budget and limit the fund to be spent on the other category.

The effect of reward promotion in category $j$ on the purchase incidences in category $i$ within the same pair is investigated through $R P_{j}$. Their coefficients in all four categories are positive and mostly significant. In contrast to the cross-effect of prices where the two category pairs display distinct relationships, the presence of reward promotions in one category consistently increase the purchase incidences in the other category within the pair. For the pair containing two substituting categories, price reductions in one category (e.g., facial lotion) decreases the purchase incidence in the other category (e.g., facial masks); but if reward promotion is provided, this negative effect can be mitigated.

Table 5 also shows the cross-category effects $\rho_{i j}$, which measure how the purchase incidence in category $i$ in a basket affects the probability of joint purchase of another category $j$. A positive/negative 
coefficient means that category $j$ is more/less likely to appear in the same basket. Within each category pair, the cross-effects are positive and significant, suggesting that joint purchases are more likely to be observed.

\subsection{Price Elasticities and Reward Ratio Elasticities}

We define price elasticity of category $i$ with respect to $j$ as the ratio of the percentage change in the probability that a consumer buys category $i$ to $1 \%$ price change in category $j$, and define the reward elasticity in a similar way. Since the minimum change of reward ratio during our sample period is .1, we calculate the semi-elasticity of the reward promotion, which is the percentage change in marginal purchase incidence relative to $10 \%$ reward increase. Cross-price and cross-reward elasticities are accordingly for $i \neq j$. The cross-price elasticity is a compound of the direct cross-category price effect and the indirect category correlation, while cross-reward elasticity mainly comes from the indirect category correlation. We calculate the individual elasticities and summarize the statistics of elasticities across all consumers in Table 6.

(Insert Table 6 about here.)

As expected, the own-price elasticities are negative, ranging from -0.563 (facial lotion) to -3.654 (facial mask), largely consistent with extant literature (e.g., Blattberg, Briesch, and Fox 1995; Nijs et al. 2001). The cross-elasticities are interesting for three reasons. First, they confirm the finding from the parameter estimates; that is, the two facial care products showed pattern of substitutes whereas the two categories in the personal hygiene pair showed typical complementarity.

Second, within each pair, the cross-elasticities are asymmetric in their absolute values. For instance, the elasticity of demand for facial lotion with respect to facial mask prices $(0.158)$ is much lower than the other way around (0.582). Manchanda et al. (1999) find similar asymmetry in their model, and refer to the category whose price has a greater effect on the other as the "primary" category of the pair. By their definition, facial lotion and shampoo would be the primary categories in their respective pairs.

Third, the cross-elasticities are uniformly much lower than the corresponding self-elasticities, consistent with previous findings such as Manchanda et al. (1999). The within-pair asymmetry is much 
greater for the facial skincare products than for the personal hygiene pair. For instance, facial lotion is a stronger driver of facial mask purchases than shampoo is of body wash purchases.

The signs of own-reward ratio elasticities are all positive, supporting our predictions. As reward ratios can increase by as much as 20 times during periods of heavy promotion (the maximum reward ratios recorded in the data period in Table 2), the results suggest that promotions offering higher reward ratios can greatly boost the sales of the promoted category. Unlike price elasticities, the two personal hygiene categories showed greater elasticities (.927 and 1.528) than the facial skincare products (.134 and .475).

The within-pair cross-category elasticities of demand with respect to reward ratios are also consistent with our hypotheses. First, within each pair, the four cross-elasticities are all positive, suggesting that reward ratios exert a positive externality on the purchase incidences of closely related categories. Second, unlike the price elasticities, the magnitudes of the cross-elasticities are not always lower than those of the self-elasticities. In particular, the incidence of facial mask is more affected by the reward ratios of facial lotion and those of its own. Third, the asymmetry in cross-category reward elasticities is evidence that one of the two categories is a more powerful driver of purchase incidence. For example, the purchase probability of facial masks changes by $1.392 \%$ in response to a $1 \%$ increase in the reward ratio offered for facial lotions, but the effect is much weaker the other way around $(0.009 \%)$.

\subsection{Substitution between Reward and Price Promotions}

The above analysis of price and reward elasticities shows that both price cuts and reward point promotions can achieve the goal of increasing short-term sales, suggesting they are substitutes in function. The rate of substitution, $R S$, captures the substitutive relationship between these two promotional tools. It represents the absolute reward ratio change that is necessary to offset $1 \%$ price increase and maintain the utility unchanged. Put differently, it measures the incremental points necessary to offset the disutility of 1 \% price increase. The rates of substitution for the four categories are shown in Table 7.

(Insert Table 7 about here.)

Taking facial lotion as an example, a 1\% price increase is offset by a 0.442 increase in its reward ratio to maintain the same utility level for the shopper. In other words, if the reward ratio of facial lotion 
increases from its usual reward ratio 0.1 to its maximum ratio 2 , it will offset about $4 \%$ price increases. A small $R S$ suggests that the perceived value of the reward ratio is relatively high since retailers do not need to offer much extra reward points to offset the negative effect of the assumed price increase. Among the four categories, body wash and shampoo have much lower $R S$ than the two facial skincare categories, which means consumers do not perceive the extra reward points to be valuable, and this helps explain why the retailer has to offer higher reward ratios in the facial skincare categories but not as high reward ratios in the personal hygiene pair as the substitute promotion for price discount.

\subsection{Return on investment of reward points}

Eq. (6) requires specific assumption about the magnitude of the profits-to-revenue ratio. For higher levels of this ratio, ROI becomes greater, anything else being equal. As we do not have this information on the specific categories at this retailer in question, we use comparable industry statistics as reference. For example, drugstores in the U.S. have a 3.0\% net profit margin on average; ${ }^{7}$ an Asian cosmetics retailing group listed in the Hong Kong Stock Exchange reports an 8\% ratio between profit after income tax and turnover in 2012. ${ }^{8}$ Thus, we chose to calculate the ROI for the nine levels of the profit/revenue ratios ranging from $2 \%$ to $10 \%$ and the results are summarized in Table 8 . When ROI is lower than one, the retailer will bear deficit from its investment, so the investment on reward promotion in the lotion category is not profitable at all profit-to-revenue ratios considered here. The return on investment of the hygiene product pair is higher than that of the facial skincare pair at any profit-to-revenue ratio. Given the fact that the facial skincare categories usually have higher profit margins than the personal hygiene categories do, it is more likely that the ROI could be higher in the facial product pair. For instance, the ROI of facial mask at $8 \%$ profit-to-revenue ratio is 1.457 , higher than the ROI of shampoo and body wash at $3 \%$ of profit-to-revenue ratio (0.969 and 1.304 respectively).

(Insert Table 8 about here.)

The actual ROI can be higher than the results shown here for two reasons. First, when reward

\footnotetext{
7 Yahoo! Finance. http://biz.yahoo.com/ic/733.html Accessed on 16 October 2013.

8 Sa Sa International Holdings Limited. http://corp.sasa.com/en/investor-relations/financial-highlights/ Accessed on 16 October 2013.
} 
promotions are used for promoting sales, the retailer does not have to incur any real costs immediately. Reward points will become "real” costs only when consumers redeem them, which may or may not happen. The huge number of unredeemed reward points in frequent flyer programs etc. is strong evidence that consumers do not redeem all the points in their accounts. The costs of the reward points may not materialize. Second, the increased reward points as a consequence of the reward promotion are future liabilities. For retailers with higher discount rates (who prefer present term revenues much more than future cash flow), reward promotions are more appealing. In the ROI calculations here, we made conservative assumptions that all the reward points will be redeemed in the future and that the retailer's discount rate is 1 . Should either of the assumptions be relaxed, the ROI associated with the reward promotion would become higher.

\section{Conclusions}

In this research, we have investigated and compared two particular forms of sales promotion: temporary price cuts and enhanced reward point ratios. Our answer to the titular question, “are points like money,” is both “yes” and “no.” On one hand, reward and price promotions both stimulate retail sales. Retailers can achieve higher sales either by providing temporary price reductions or by awarding more points per unit of monetary payment while keeping prices unchanged. On the other hand, reward promotions and price reductions work differently. Especially for categories that appear to be substitutes according to their cross price elasticities, reward promotions in one category still has positive effect on the other category. We have quantified the rates of substitution between offered reward ratios and prices in four product categories.

However, perhaps the most important difference between price and reward promotions lies in the nature of their costs and benefits to the retailer. While price discounts are "real" and immediate monetary costs, reward promotions may turn out to be purely profitable if many consumers simply do not redeem their points as described in the opening quotes from the Economist. For retailers with higher discount rates, reward promotions are more preferable than immediate price cuts since they do not eat into cash 
flow in the present term.

Future research on this topic should consider the effects of consumer sensitivity of choice shares to reward point promotions and price discounts. For example, some segments of the population are more responsive to immediate price discounts, while others prefer to accumulate reward points. Proper segmentation can facilitate targeted marketing strategies and improve profitability. Second, this research does not discuss the effects of point redemption policies on consumer purchase decisions. Redemption decision depends on many factors such as the minimum threshold points to redeem any merchandise (Kivetz and Simonson 2002), the pricing scheme of the retailer (e.g., Drèze and Nunes 2004), and points pressure resulted from the loyalty program tiers (Drèze and Nunes 2008; Kopalle et al. 2012). Many questions related to redemption behavior remain unanswered. For example, it would be interesting to see which categories consumers tend to spend their earned points on. Though the underlying behavioral mechanisms behind category purchase decisions are beyond the scope of this research, they warrant further study. 


\section{References}

Berman, B. (2006). Developing an Effective Customer Loyalty Program. California Management Review, 49(1), 123-148.

Blattberg, R. C., Briesch, R., \& Fox, E. J. (1995). How Promotions Work. Marketing Science, 14(3), G122-G132.

Bolton, R. N., Kannan, P. K., \& Bramlett, M. D. (2000). Implications of Loyalty Program Membership and Service Experiences for Customer Retention and Value. Journal of the Academy of Marketing Science, 28(1), 95-108.

Dorotic, M., Fok, D., Verhoef, P. C., \& Bijmolt, T. H. A. (2011). Do Vendors Benefit From Promotions in a Multi-Vendor Loyalty Program? Marketing Letters, 22(4), 341-356.

Duvvuri, S. D., Ansari, A., \& Gupta, S. (2007). Consumers’ Price Sensitivities Across Complementary Categories. Management Science, 53(12), 1933-1945.

Drèze, X., \& Hoch, S. J. (1998). Exploiting the Installed Base Using Cross-Merchandising and Category Destination Programs. International Journal of Research in Marketing, 15(5), 459-471.

Drèze, X., \& Nunes, J. C. (2004). Using Combined-Currency Prices to Lower Consumers' Perceived Cost. Journal of Marketing Research, 41(1), 59-72.

Drèze, X., J. C. Nunes. (2008). Feeling Superior: The Impact of Loyalty Program Structure on Consumers' Perceptions of Status. Journal of Consumer Research, 35(6), 890-905.

The Economist. (2005). In terminal decline? January 6.

Hartmann, W. R., \& Viard, V. B. (2008). Do Frequency Reward Programs Create Switching Costs? A Dynamic Structural Analysis of Demand in a Reward Program. Quantitative Marketing Economics, 6(2), 109-137.

Henderson, C. M., Beck, J. T., \& Palmatier, R. W. (2011). Review of the theoretical underpinnings of loyalty programs. Journal of Consumer Psychology, 21(3), 256-276.

Keh, H. T., \& Lee, Y. H. (2006). Do Reward Programs Build Loyalty for Services? The Moderating Effect of Satisfaction on Type and Timing of Rewards. Journal of Retailing, 82(2), 127-136.

Kivetz, R., \& Simonson, I. (2002). Earning the Right to Indulge: Effort as a Determinant of Customer Preferences Toward Frequency Program Rewards. Journal of Marketing Research, 39(2), 155-170. Kivetz, R., Urminsky, O., \& Zheng, Y. (2006). The Goal-Gradient Hypothesis Resurrected: Purchase Acceleration, Illusionary Goal Progress, and Customer Retention. Journal of Marketing Research, 43(1), 39-58.

Kopalle, P.K., Sun, Y., Neslin, S.A., Sun, B., \& Swaminathan, V. (2012) The Joint Sales Impact of Frequency Reward and Customer Tier Components of Loyalty Programs. Marketing Science, 31(2), 216-235. 
Lal, R. \& Bell, D. E. (2003). The Impact of Frequent Shopper Programs in Grocery Retailing. Quantitative Marketing and Economics, 1(2), 179-202.

Leeflang, P. S. H., \& Parreño-Selva, J. (2012). Cross-Category Demand Effects of Price Promotions. Journal of the Academy of Marketing Science, 40(4), 572-586.

Lewis, M. (2004). The Influence of Loyalty Programs and Short-Term Promotions on Customer Retention. Journal of Marketing Research, 41(3), 281-292.

Liu, Y. (2007). The Long-Term Impact of Loyalty Programs on Consumer Purchase Behavior and Loyalty. Journal of Marketing, 71(4), 19-35.

Manchanda, P., Ansari, A., \& Gupta, S. (1999). The "Shopping Basket”: A Model for Multicategory Purchase Incidence Decisions. Marketing Science, 18(2), 95-114.

Mauri, C. (2003). Card Loyalty: A New Emerging Issue in Grocery Retailing. Journal of Retailing and Consumer Services, 10(1), 13-25.

Melnyk, V., \& van Osselaer, S. M. J. (2012). Make Me Special: Gender Differences in Consumers’ Responses to Loyalty Programs. Marketing Letters, 23(3), 545-559.

Narasimhan, C., Neslin, S. A., \& Sen, S. K. (1996). Promotional Elasticities and Category Characteristics. Journal of Marketing, 60(2), 17-30.

Nijs, V. R., Dekimpe, M. G., Steenkamps, J.-B. E. M., \& Hanssens, D. M. (2001). The Category-Demand Effects of Price Promotions. Marketing Science, 20(1), 1-22.

Postrel, R., \& Hlavinka, K. (2012). An Open Economy: The Evolution of Loyalty in the United States. Colloquy.com.

Russell, G. J., Ratneshwar, S., Shocker, A. D., Bell, D., Bodapati, A., Degeratu, A., Hildebrandt, L., Kim, N., Ramaswami, S., \& Shankar, V. H. (1999). Multiple-Category Decision-Making: Review and Synthesis. Marketing Letters, 10(3), 319-332.

Seetharaman, P. B., Chib, S., Ainslie, A., Boatwright, P., Chan, T., Gupta, S., Mehta, N., Rao, V., \& Strijnev, A. (2005). Models of Multi-Category Choice Behavior. Marketing Letters, 16(3,4), 239-254.

Taylor, G. A., \& Neslin, S. A. (2005). The Current and Future Sales Impact of a Retail Frequency Reward Program. Journal of Retailing, 81(4), 293-305.

Yi, Y., \& Jeon, H. (2003). Effects of Loyalty Programs on Value Perception, Program Loyalty, and Brand Loyalty. Journal of the Academy of Marketing Science, 31(3), 229-240.

Zhang, J., \& Breugelmans, E. (2012). The Impact of an Item-based Loyalty Program on Consumer Purchase Behavior. Journal of Marketing Research, 49(1), 50-65. 
Table 1. Breakdown of Reward Program Members by Purchasing Frequency

\begin{tabular}{lccc}
\hline No. of Purchases & No. of Members & Percent & Cumulative percent \\
\hline 1 & 5,136 & 29.91 & 29.91 \\
2 & 3,281 & 19.11 & 49.02 \\
3 & 2,279 & 13.27 & 62.29 \\
4 & 1,596 & 9.29 & 71.59 \\
5 & 1,115 & 6.49 & 78.08 \\
$\geq 6$ & 3,764 & 21.92 & 100.00 \\
TOTAL & 17,171 & 100.00 & \\
\hline
\end{tabular}

Table 2. Descriptive Statistics of the Sample

\begin{tabular}{l|r|r|r|r}
\hline & \multicolumn{4}{|c}{ Price (yuan) } \\
\cline { 2 - 5 } & Facial lotion & Facial mask & Shampoo & Body wash \\
\hline Mean & 591.44 & 269.61 & 23.40 & 19.63 \\
S.D. & 404.29 & 55.75 & 8.19 & 4.54 \\
MIN & 16.67 & 42.00 & 6.42 & 5.40 \\
MAX & 6666.67 & 1135.00 & 216.00 & 189.00 \\
\hline
\end{tabular}

\begin{tabular}{l|r|r|r|r}
\hline & \multicolumn{4}{|c}{ Reward Ratio (points per yuan) } \\
\cline { 2 - 5 } & Facial lotion & Facial mask & Shampoo & Body wash \\
\hline Mean & 0.41 & 0.44 & 0.12 & 0.11 \\
S.D. & 0.50 & 0.47 & 0.08 & 0.05 \\
MIN & 0.09 & 0.09 & 0.09 & 0.09 \\
MAX & 2.00 & 2.00 & 0.50 & 0.50 \\
\hline
\end{tabular}

\begin{tabular}{l|r|r|r|r}
\hline & \multicolumn{4}{|c}{ Reward Promotion } \\
\cline { 2 - 5 } & Facial lotion & Facial mask & Shampoo & Body wash \\
\hline Mean & 0.39 & 0.82 & 0.07 & 0.10 \\
S.D. & 0.49 & 0.38 & 0.26 & 0.29 \\
\hline
\end{tabular}

\begin{tabular}{l|c|c|c}
\hline & Cumulative Reward Points & Age & Sex \\
\hline Mean & 2861.05 & 36.36 & 0.86 \\
S.D. & 10041.90 & 8.91 & 0.35 \\
MIN & 0.00 & 16.00 & 0.00 \\
MAX & $620,572.40$ & 79.00 & 1.00 \\
\hline
\end{tabular}


Table 3. Joint Pairwise Purchase Incidence in Estimation Sample

\begin{tabular}{c|crrrr}
\hline & $\begin{array}{c}\text { Facial Lotion } \\
(\mathbf{L})\end{array}$ & $\begin{array}{c}\text { Facial Mask } \\
(\mathbf{M})\end{array}$ & $\begin{array}{c}\text { Shampoo } \\
\text { (S) }\end{array}$ & \multicolumn{2}{c}{$\begin{array}{c}\text { Body Wash } \\
\text { (W) }\end{array}$} \\
\hline L & 20,173 & & 738 & 201 & 62 \\
M & & & 720 & 7 & 2 \\
S & & & 6,366 & 670 \\
W & & & & 1,460 \\
\hline
\end{tabular}

Table 4. Observed vs. Predicted Purchase Incidences

\begin{tabular}{|c|c|c|c|c|c|}
\hline Basket Type & Observed & Predicted & Basket Type & Observed & Predicted \\
\hline Null & 47,444 & 47,315 & Null & 60,579 & 60,648 \\
\hline $\mathrm{L}$ & 20,458 & 20,604 & S & 6,581 & 6,532 \\
\hline M & 729 & 749 & W & 1,526 & 1,582 \\
\hline LM & 748 & 711 & SW & 693 & 617 \\
\hline Total & 69,379 & 69,379 & Total & 69,379 & 69,379 \\
\hline Hit rate & \multicolumn{2}{|c|}{$99.52 \%$} & Hit Rate & \multicolumn{2}{|c|}{$99.64 \%$} \\
\hline
\end{tabular}

L - Facial lotion, M - Facial mask, S - Shampoo, W - Body wash. 
Table 5. Parameter Estimates

\begin{tabular}{|c|c|c|c|c|c|}
\hline & $\begin{array}{c}\text { Facial Lotion } \\
\text { (L) }\end{array}$ & $\begin{array}{c}\text { Facial Mask } \\
\text { (M) }\end{array}$ & & $\begin{array}{l}\text { Shampoo } \\
\text { (S) }\end{array}$ & $\begin{array}{c}\text { Body Wash } \\
\text { (W) }\end{array}$ \\
\hline $\operatorname{lnPrice}_{L}$ & $\begin{array}{c}-0.3971 \\
(47.47)^{* *} \\
\end{array}$ & $\begin{array}{c}0.1949 \\
(11.07)^{* *} \\
\end{array}$ & InPrices $_{S}$ & $\begin{array}{r}-0.8818 \\
(29.56)^{* *}\end{array}$ & $\begin{array}{l}-0.1461 \\
(4.21)^{* *} \\
\end{array}$ \\
\hline $\operatorname{lnPrice}_{M}$ & $\begin{array}{c}0.1369 \\
(4.56)^{* *}\end{array}$ & $\begin{array}{c}-0.9097 \\
(20.75)^{* *}\end{array}$ & InPrice $_{W}$ & $\begin{array}{r}-0.0996 \\
(3.41)^{* *} \\
\end{array}$ & $\begin{array}{c}-0.9347 \\
(20.05)^{* *}\end{array}$ \\
\hline RRatio $_{L}$ & $\begin{array}{c}0.7961 \\
(15.13)^{* *}\end{array}$ & & RRatio $_{S}$ & $\begin{array}{r}4.4917 \\
(8.46)^{* *}\end{array}$ & \\
\hline RPromo $_{M}$ & $\begin{array}{c}0.0373 \\
(2.48)^{*} \\
\end{array}$ & & RPromo $_{W}$ & $\begin{array}{c}0.0817 \\
(2.21)^{*} \\
\end{array}$ & \\
\hline RPromo_Price $_{L}$ & $\begin{array}{c}-0.0952 \\
(31.58)^{* *}\end{array}$ & & RPromo_Prices & $\begin{array}{r}-0.5230 \\
(14.57)^{* *} \\
\end{array}$ & \\
\hline Sex_lnPrice $_{L}$ & $\begin{array}{l}0.0063 \\
(1.95)\end{array}$ & & Sex_InPrices & $\begin{array}{r}-0.0316 \\
(3.01)^{* *}\end{array}$ & \\
\hline Age_lnPrice $_{L}$ & $\begin{array}{l}-0.0005 \\
(4.08)^{* *}\end{array}$ & & Age_InPrices $_{\text {S }}$ & $\begin{array}{c}0.0010 \\
(2.25)^{*}\end{array}$ & \\
\hline Sex_Reward $L$ & $\begin{array}{c}0.0055 \\
(0.18) \\
\end{array}$ & & Sex_Reward $_{S}$ & $\begin{array}{r}-0.2752 \\
(1.20) \\
\end{array}$ & \\
\hline Age_Reward ${ }_{L}$ & $\begin{array}{c}0.0035 \\
(3.04)^{* *}\end{array}$ & & Age_Rewards & $\begin{array}{r}0.0110 \\
(1.16)\end{array}$ & \\
\hline Cumu_RPoint $_{L}$ & $\begin{array}{l}0.0000 \\
(0.75)\end{array}$ & & Cumu_RPoints & $\begin{array}{r}-0.0002 \\
(10.71)^{* *}\end{array}$ & \\
\hline Constant $_{L}$ & $\begin{array}{c}0.9979 \\
(5.95)^{* *}\end{array}$ & & Constants & $\begin{array}{r}1.3070 \\
(11.38)^{* *}\end{array}$ & \\
\hline RRatio $_{M}$ & & $\begin{array}{c}1.1675 \\
(10.19)^{* *}\end{array}$ & RRatio $_{W}$ & & $\begin{array}{c}4.9613 \\
(5.89)^{* *} \\
\end{array}$ \\
\hline $\operatorname{RPromo}_{L}$ & & $\begin{array}{c}0.3657 \\
(9.02)^{* *}\end{array}$ & RPromos & & $\begin{array}{l}0.0071 \\
(0.08)\end{array}$ \\
\hline RPromo_Price ${ }_{M}$ & & $\begin{array}{c}-0.3299 \\
(29.39)^{* *}\end{array}$ & RPromo_Price $_{W}$ & & $\begin{array}{c}-0.4105 \\
(11.60)^{* *}\end{array}$ \\
\hline Sex_InPrice $_{M}$ & & $\begin{array}{c}0.0173 \\
(1.66)\end{array}$ & Sex_InPrice $_{W}$ & & $\begin{array}{l}-0.0363 \\
(2.02)^{*}\end{array}$ \\
\hline Age_lnPrice $_{M}$ & & $\begin{array}{l}-0.0016 \\
(3.96)^{* *}\end{array}$ & Age_lnPrice $_{W}$ & & $\begin{array}{l}0.0007 \\
(0.90)\end{array}$ \\
\hline Sex_Reward $_{M}$ & & $\begin{array}{l}-0.0940 \\
(1.51)\end{array}$ & Sex_Reward $_{W}$ & & $\begin{array}{l}-0.7164 \\
(1.79)\end{array}$ \\
\hline Age_Reward $_{M}$ & & $\begin{array}{c}0.0037 \\
(1.53)\end{array}$ & Age_Reward $W$ & & $\begin{array}{c}0.0133 \\
(0.74) \\
\end{array}$ \\
\hline Cumu_RPoint $_{M}$ & & $\begin{array}{l}-0.0000 \\
(0.01)\end{array}$ & Cumu_RPoint $_{W}$ & & $\begin{array}{l}-0.0001 \\
(3.76)^{* *}\end{array}$ \\
\hline Constant $_{M}$ & & $\begin{array}{c}2.2440 \\
(9.83)^{* *}\end{array}$ & Constant $_{W}$ & & $\begin{array}{c}0.8798 \\
(6.02)^{* *} \\
\end{array}$ \\
\hline $\begin{array}{l}\text { Cross-category } \\
\text { effects }\left(\rho_{L M}\right)\end{array}$ & \multicolumn{2}{|l|}{$\begin{array}{c}0.3055 \\
(16.65)^{* *} \\
\end{array}$} & $\begin{array}{l}\text { Cross-category } \\
\text { effects }\left(\rho_{S W}\right)\end{array}$ & \multicolumn{2}{|c|}{$\begin{array}{c}0.3522 \\
(23.59)^{* *} \\
\end{array}$} \\
\hline
\end{tabular}

Student's $t$ statistics are in parentheses. ${ }^{* *} p<.01$, and $* p<.05$. 
Table 6. Mean Price and Reward Elasticities

\begin{tabular}{|c|c|c|c|c|}
\hline \multirow[b]{2}{*}{ Price of } & \multicolumn{4}{|c|}{ Incidence of } \\
\hline & $\mathbf{L}$ & $\mathbf{M}$ & $\mathrm{S}$ & $\mathbf{W}$ \\
\hline Facial Lotion (L) & $\begin{array}{r}-.563 \\
(.206)\end{array}$ & $\begin{array}{r}.582 \\
(.158)\end{array}$ & & \\
\hline Facial Mask (M) & $\begin{array}{r}.158 \\
(.048)\end{array}$ & $\begin{array}{r}-3.654 \\
(1.078)\end{array}$ & & \\
\hline Shampoo (S) & & & $\begin{array}{r}-1.499 \\
(.504)\end{array}$ & $\begin{array}{r}-.319 \\
(.036)\end{array}$ \\
\hline \multirow[t]{3}{*}{ Body Wash (W) } & & & $\begin{array}{r}-.168 \\
(.025) \\
\end{array}$ & $\begin{array}{r}-2.06 \\
(.587) \\
\end{array}$ \\
\hline & \multicolumn{4}{|c|}{ Incidence of } \\
\hline & $\mathbf{L}$ & $\mathbf{M}$ & $\mathrm{S}$ & $\mathbf{W}$ \\
\hline Facial Lotion (L) & $\begin{array}{r}.134 \\
(.045)\end{array}$ & $\begin{array}{r}1.392 \\
(1.294)\end{array}$ & & \\
\hline Facial mask (M) & $\begin{array}{l}.009 \\
(.02) \\
\end{array}$ & $\begin{array}{r}.475 \\
(.16) \\
\end{array}$ & & \\
\hline Shampoo (S) & & & $\begin{array}{r}.927 \\
(.386)\end{array}$ & $\begin{array}{r}.015 \\
(.005)\end{array}$ \\
\hline Body wash (W) & & & $\begin{array}{r}.138 \\
(.051) \\
\end{array}$ & $\begin{array}{l}1.528 \\
(.485) \\
\end{array}$ \\
\hline
\end{tabular}

Standard deviations are in parentheses.

Table 7. Average Rates of Substitution between Reward Points Promotion and Price Promotion

\begin{tabular}{c|c|c|c|c}
\hline & Facial Lotion (L) & Facial Mask (M) & Shampoo (S) & Body Wash (W) \\
\hline \multirow{2}{*}{ RS } & 0.442 & 0.780 & 0.226 & 0.205 \\
& $(0.010)$ & $(0.018)$ & $(4.81)$ & $(0.087)$ \\
\hline
\end{tabular}

Standard deviations are in parentheses.

Table 8. Return on Investment (ROI)

\begin{tabular}{c|c|c|c|c}
\hline Profit/Revenue & Facial Lotion & Facial Mask & Shampoo & Body Wash \\
\hline $2 \%$ & 0.142 & 0.364 & 0.646 & 0.869 \\
\hline $3 \%$ & 0.214 & 0.546 & 0.969 & 1.304 \\
\hline $4 \%$ & 0.285 & 0.728 & 1.293 & 1.739 \\
\hline $5 \%$ & 0.356 & 0.910 & 1.616 & 2.174 \\
\hline $6 \%$ & 0.427 & 1.093 & 1.939 & 2.608 \\
\hline $7 \%$ & 0.498 & 1.275 & 2.262 & 3.043 \\
\hline $8 \%$ & 0.570 & 1.457 & 2.585 & 3.478 \\
\hline $9 \%$ & 0.641 & 1.639 & 2.908 & 3.913 \\
\hline $10 \%$ & 0.712 & 1.821 & 3.231 & 4.347 \\
\hline
\end{tabular}

